\title{
Preface
}

\section{6th Brazilian Congress of Mechanical Engineering: Symposium on Vibration and Acoustics}

The 16th Brazilian Congress of Mechanical Engineering (COBEM 2001) was held on November 2630, 2001 in Uberlândia, Minas Gerais, Brazil, to bring together professionals from industries, universities and research centers in order to share experiences and to discuss the main advances and trends of Mechanical Engineering and related sciences. Under the patronage of the Brazilian Society of Mechanical Sciences (ABCM), COBEM has been biannually held in different places around the country, since 1971. The 16th edition of COBEM was organized by the School of Mechanical Engineering of the Federal University of Uberlândia.

The 16th COBEM was organized according to 19 different symposia covering the main areas of mechanical sciences. One of these symposia was the Symposium of Vibration and Acoustics. Topics covered in the symposium include:

\section{Vibroacoustics Systems \\ Modal Analysis Techniques \\ Identification and Monitoring \\ Model Updating \\ Vibration and Noise Control \\ Fluid-Structure Interaction \\ Mechanical Engineering Education;}

Ten research papers were selected for the present special issue, from the sixty papers presented in the Symposium and published in the Congress Proceedings. The papers included in this issue were edited with the same quality standards as for regular issue papers, following the standard reviewing and revision processes of Shock and Vibration.

A special note of gratitude goes to all participants whose attendance and contributions helped to foster important discussions on issues associated with vibration and noise problems. Special thanks are due to the coordinator of the Symposium of Vibration and Acoustics, Professor J.J. de Espíndola of Federal University of Santa Catarina, and to the technical committee of the Symposium, Prof. A. Fleury (IPT-SP), Dr. C. Bavastri (UFSC), Prof. D. Rade (UFU), Dr. F. Bázan (UFSC), Mr. J.M. Silva Neto (UFSC), Prof. J.M. Balhazar (UNESP-RC), Prof. L.C.S. Goes (ITA), Prof. M. Mucheroni (EESC-USP), Prof. N. Roitman (COPPEUFRJ), Prof. P.T.R. Mendonça (UFSC), Prof. P.R.G. Kurka (UNICAMP), Prof. R. Pederiva (UNICAMP) and Prof. V. Lopes, Jr (UNESP-IS). The support of Prof. D. Rade of Federal University of Uberlândia in helping with the reviewing procedure is greatly appreciated. Finally, the efforts of Prof. D. Inman, Editorin-Chief of Shock and Vibration, in editing this special issue are greatly appreciated.

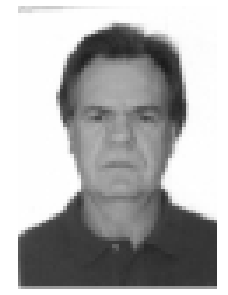

Prof. Valder Steffen, Jr

Guest Editor

Federal University of Uberlândia

School of Mechanical Engineering

Campus Santa Mônica

38400-902 Uberlândia, MG, Brazil 

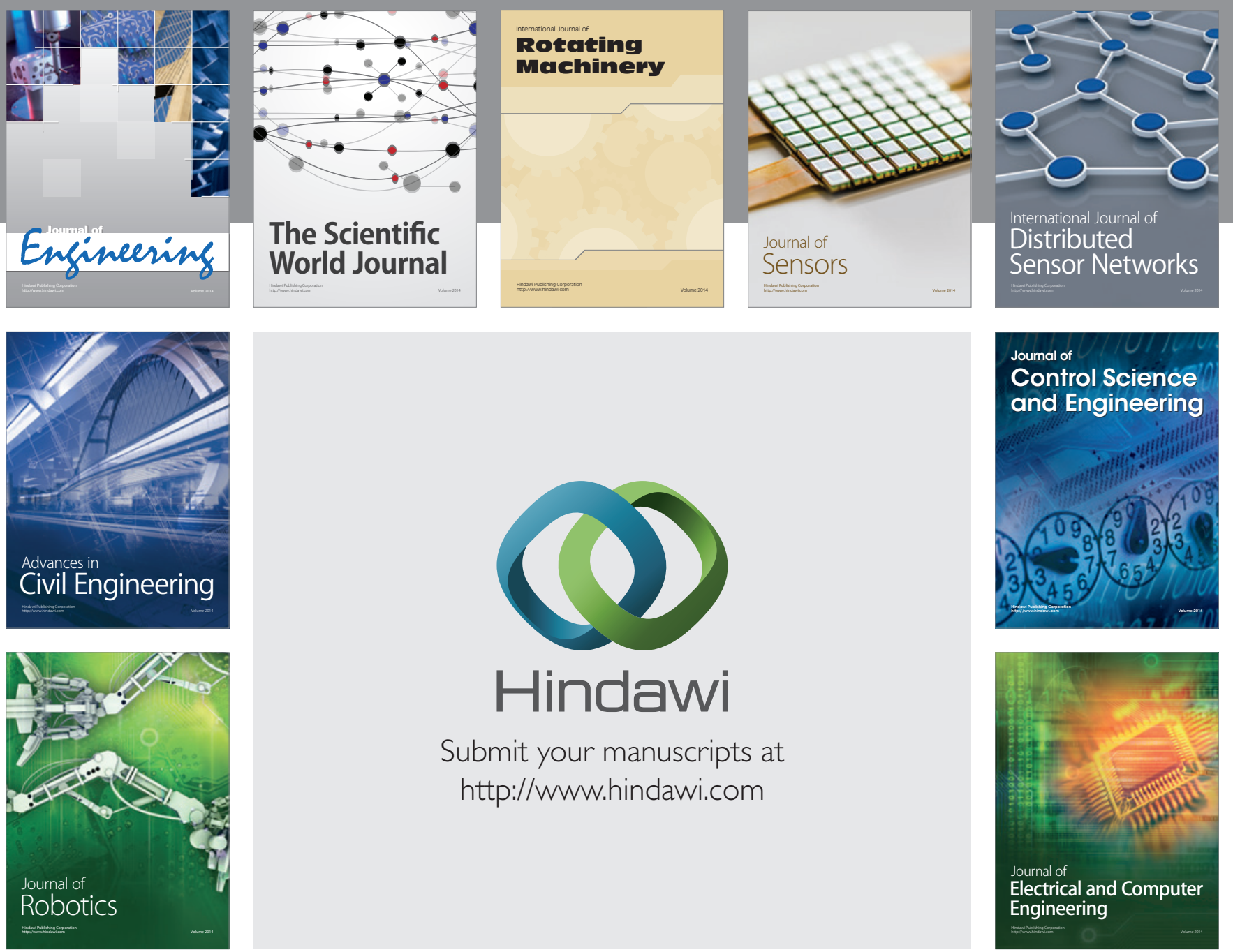

Submit your manuscripts at

http://www.hindawi.com
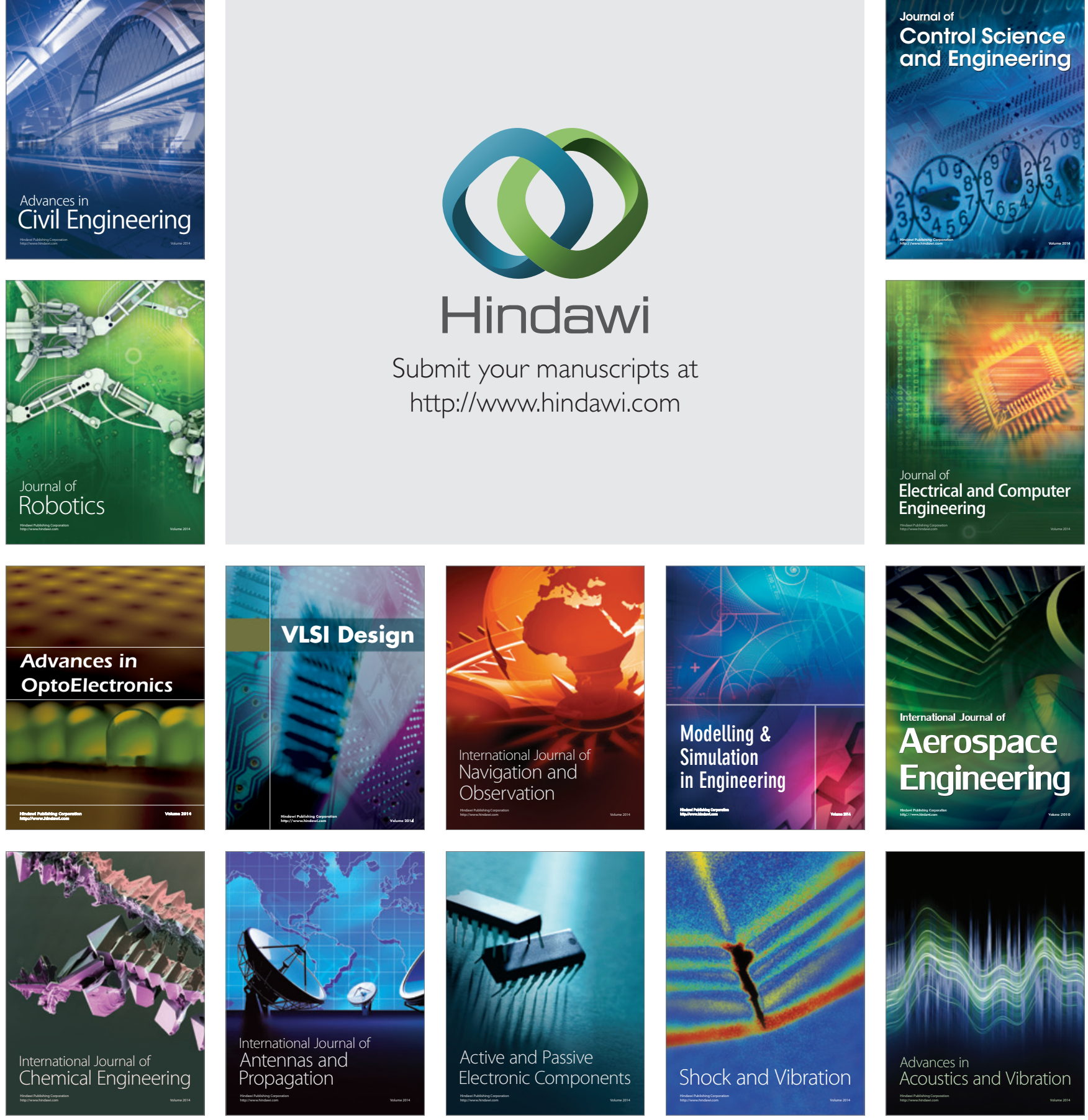